ESTUDIOS

\title{
O direito de greve como manifestação do exercício da democracia: Análise da decisão do TST sobre a legitimidade da greve política
}

\author{
The right to strike as a manifestation of democracy exercise: \\ Analysis of the TST decision on the legitimacy of the political strike
}

\author{
Ana Virgínia Moreira Gomes \\ Universidade de Fortaleza, Brasil \\ Flavia Aguiar Cabral Furtado Pinto \\ Universidade Estadual do Ceará, Brasil \\ Carlos Eduardo Furtado Pinto \\ Universidade de Fortaleza, Brasil
}

\begin{abstract}
RESUMO Esta pesquisa analisa quais as possibilidades e os limites do direito de greve política como manifestação do exercício da democracia, examinando decisão proferida pelo Tribunal Superior do Trabalho no Brasil. O estudo inicia por examinar a relação entre liberdade sindical, direito de greve e exercício da democracia. A seguir, o artigo sistematiza a legislação brasileira e internacional sobre liberdade sindical e direito de greve. Por fim, a pesquisa considera se o direito de greve pode ser exercido diretamente em face do Estado. O estudo propõe que limitações constitucionais e legais no plano nacional e internacional ao exercício do direito de greve não implicam no reconhecimento restrito do direito de greve, abrangendo apenas as relações entre empregado e empregador. Assumir a possibilidade do exercício do direito de greve diante do Estado significa entender seu papel fundamental de instrumento político para a participação democrática dos trabalhadores.
\end{abstract}

PALAVRAS-CHAVE Direito de greve, greve política, liberdade sindical, democracia.

ABSTRACT This research analyzes the possibilities and limits of the right to political strike as a manifestation of the exercise of democracy, examining a Superior Labor Court decision in Brazil. The study starts by examining the relationship between 


\begin{abstract}
freedom of association, right to strike and the exercise of democracy. Next, the paper systematizes Brazilian and international legislation on freedom of association and the right to strike. Finally, it considers whether the right to strike can be exercised directly against the State. The study proposes that constitutional and legal limitations at the national and international levels to the exercise of the right to strike do not imply the restricted recognition of the right to strike, covering only relations between employees and employers. To assume the possibility of exercising the right to strike in face of the State means to understand its fundamental role as a political instrument for workers' democratic participation.
\end{abstract}

KEYWORDS Right to strike, political strike, freedom of association, democracy.

\title{
Introdução
}

O direito de greve é um direito fundamental que no seu exercício desafia expressamente o direito à propriedade dos empregadores, em razão da paralização dos serviços; além de, por vezes, ocasionar desestabilidades sociais e econômicas para além da empresa. Como os demais direitos fundamentais, o direito fundamental à greve não pode ser exercido de forma absoluta, sofrendo limitações constitucionais e legais.

Essas ponderações, no entanto, não implicam na restrição do reconhecimento do direito de greve, por exemplo, limitando-o às relações estreitas entre empregado e empregador. O Estado pode também assumir um dos polos da relação, em situações que envolvam, em última análise, a garantia ao direito fundamental ao trabalho ou à seguridade social ou à saúde e segurança dos trabalhadores, já que o direito de greve também constitui um instrumento para possibilitar a participação dos trabalhadores nas decisões políticas que os afetam, permitindo o pleno exercício da cidadania e o fortalecimento da democracia.

Esta pesquisa tem como objetivo geral analisar quais as possibilidades e os limites do direito de greve como manifestação do exercício da democracia, tomando como base o estudo de caso referente à decisão proferida pelo Tribunal Superior do Trabalho (TST) nos autos do processo 1000418-66.2018.5.00.00oo do Dissídio Coletivo de Greve (DCG) na Ação declaratória de nulidade de greve. Nessa decisão, não foi reconhecida como legítima a chamada greve política. Para a análise dos argumentos desenvolvidos nessa decisão, o estudo inicia por examinar a relação entre a liberdade sindical e o direito de greve, bem como suas implicações para o exercício da democracia. A seguir, o artigo sistematiza a legislação pátria e internacional sobre liberdade sindical e direito de greve aplicáveis no sistema de relações de trabalho brasileiro, em especial no que concerne às Convenções 87 e 98 da OIT sobre o exercício da liberdade sindical e da negociação coletiva. Apesar de não ratificada, a Convenção 87 exerce influência significativa no contexto do direito coletivo do trabalho no país, 
em razão de assegurar o princípio da liberdade sindical, princípio constitucional da OIT que vincula todos os seus Estados membros. Ademais, fundada em decisão do Comitê de Liberdade Sindical da OIT, a OIT compreende que o princípio da liberdade sindical expresso na Convenção 87 abrange o direito de greve.

Por fim, a pesquisa considera se o direito de greve pode ser exercido diretamente em face do Estado, considerando a decisão do TST. O capítulo trata especificamente da decisão em que a corte decidiu, por maioria, pela ilegalidade da greve dos funcionários da Eletrobrás por entender que a alegação de ameaça de privatização da empresa não se enquadra como um motivo capaz de justificar o exercício do direito de greve, uma vez que esse direito somente pode ser exercido em face do empregador (o que não ocorreu no caso) e não em face do Estado.

A metodologia empregada para a realização da pesquisa classifica-se como qualitativa e bibliográfica, por meio de livros, artigos científicos, jurisprudência e legislação pátria e estrangeira aplicada ao Brasil acerca da liberdade sindical, do direito de greve e do exercício da democracia. Entre os autores pesquisados destacam-se Delgado (2014), Kolben (2016) e Lima (2014).

Ao final, o estudo propõe que a legitimidade do exercício da greve política é essencial como forma de contribuir para a efetividade do exercício da liberdade sindical e do direito de greve no Estado Democrático brasileiro.

\section{A função democrática do direito de greve e da liberdade sindical}

Os limites e potenciais do exercício do direito de greve estão intimamente ligados ao tipo de Estado e ao sistema político adotado em cada país. Marques de Lima (2014) observa que o Estado liberal é delineado a partir dos valores da autonomia individual, do estímulo ao livre comércio e da mínima intervenção estatal na economia. A organização coletiva de trabalhadores e a sua atuação, como no caso das greves, eram consideradas desordens que precisavam ser coibidas.

A partir de movimentos sociais que se intensificaram no contexto da Primeira Guerra Mundial e da crise de 1929, o Estado passou a intervir nas relações econômicas e sociais, buscando equilibrar as relações entre capital e trabalho. O Estado Social, fundado no valor da justiça social e visando a erradicação de desigualdades materiais, se estrutura nesse novo contexto econômico e político. E é nesse Estado que a questão trabalhista passa a ter legitimidade e o direito do trabalho se sistematiza, por um lado, adotando norma individuais protetoras, e, por outro, garantindo a autonomia dos sindicatos e a atuação coletiva, como a negociação letiva e a greve.

$\mathrm{Na}$ contemporaneidade, em Estados democráticos de direito a liberdade sindical e o direito de greve são assegurados como direitos fundamentais dos trabalhadores, meios para a expressão democrática dos grupos sociais. Conforme destaca Lima (2014: 104): 
O direito de greve consegue uma acomodação mais consentânea no Estado Democrático de direito, porque sua feição tipicamente fundamental insere-se na categoria dos direitos sociais, sendo balizado por um ordenamento jurídico que espanca as situações abusivas e, ao mesmo tempo, estabelece regramentos básicos de sua deflagração e desenvolvimento. Além de tipifica-lo como direito fundamental, o que lhe dá especial potencialidade, a Constituição democrática o acolhe na ambivalência das liberdades de reivindicação e de manifestação, como essencial ao equilíbrio das forças produtivas. Este Estado trata a greve como movimento organizado de grupos, a merecer a tutela do Poder Público, dentro de uma certa razoabilidade, ao mesmo tempo em que cria uma rede intrincada de outros direitos fundamentais com os quais convive, na interdisciplinaridade.

No Brasil, observa-se uma tradição autoritária acerca do direito de greve que perdurou ao longo do século XX. A primeira menção à greve no ordenamento jurídico brasileiro, conforme análise histórica feita por Baboin (2013), ocorreu por meio da entrada em vigor do Código Penal em outubro de 189o. Naquela oportunidade, a greve foi definida como ilícito criminal. Em razão da pressão da classe operária, dois meses depois essa conduta deixou de ser criminalizada, por meio do Decreto 1.162 de 12 de dezembro de 1890 . No entanto, na prática, as autoridades policiais e administrativas continuaram a negar a fruição desse direito.

A Carta Constitucional de 1934, promulgada após a Revolução de 1930, não fez qualquer referência ao direito de greve. Já a Constituição de 1937, uma constituição explicitamente corporativista, proibiu a greve e o lock out. O Código Penal de 1940, em seu artigo 201, criminalizou a participação em greves em serviços públicos ou que prejudicassem o andamento de obras públicas. Em 1943, a Consolidação das Leis do Trabalho também proibiu o direito de greve e o lock-out.

A partir da Constituição de 1946, o direito de greve foi finalmente admitido, no entanto, seu exercício ficou condicionado à existência de lei regulamentadora que demorou a ser editada, razão pela qual, permaneceu restrito aos casos de atividades acessórias, nos termos do Decreto-lei 9.070 de 1946 sancionado pelo então Presidente da República, General Eurico Gaspar Dutra.

Em 1964, durante a ditadura militar, a Lei 4.330 regulamentou o direito de greve previsto na Constituição Federal de 1946. No entanto, após a promulgação da Constituição Federal de 1967, o direito de greve foi mais uma vez restringido, por meio do artigo $157, \S 7^{\circ}$, que o proibiu nos casos de serviços públicos e atividades essenciais. O Decreto-Lei 898 de 29 de setembro de 1969, por sua vez, além de estabelecer penalidades para os casos de descumprimento do artigo 157, $\$ 7^{\circ}$ da Constituição Federal de 1946, estabeleceu penalidades para as greves políticas consideradas subversivas.

Mesmo nesse contexto de intensa repressão aos movimentos paredistas, de acordo com Baboin (2013), as greves permaneceram eclodindo, tendo sido registradas, no final de 1978, 118 greves em todo o território nacional. Em reação, foi editado, no 
mesmo ano, o Decreto-Lei 1.632, o qual proibiu a greve em serviços essenciais de interesse da segurança nacional, o que, na prática poderia inviabilizar o próprio exercício do direito de greve.

A partir da redemocratização, a Constituição Federal de 1988 define o Estado brasileiro como um Estado Democrático de Direito, nos termos do seu artigo $1^{\circ}$ : «A República Federativa do Brasil, formada pela união indissolúvel dos Estados e Municípios e do Distrito Federal, constitui-se em Estado Democrático de Direito».

$\mathrm{O}$ ordenamento jurídico passa a aliar, tanto normas que asseguram o respeito às leis, à liberdade, à segurança e à manutenção da ordem, quanto normas que garantam e promovam a participação dos cidadãos nas decisões políticas do país. No que concerne às relações coletivas de trabalho, contudo, a liberdade de sindical não é assegurada plenamente. Delgado (2001: 81) observa que a pouca valorização dos princípios especiais do Direito Coletivo comprometeu o correto enfrentamento dos problemas inerentes ao sistema democrático, uma vez que «a não compreensão da essencialidade da noção de ser coletivo, da relevância de ser ele representativo e consistente para de fato assegurar condições de equivalência entre os sujeitos do ramo juscoletivo trabalhista, simplesmente dilapida toda a noção de Direito Coletivo do Trabalho e de agentes coletivos atuando em nome dos trabalhadores». Para além das restrições constitucionais e legais à liberdade sindical e ao direito de greve, observa-se que esses permanecem não sendo encarados como direitos fundamentais decorrentes do pleno exercício da democracia. ${ }^{1}$ Continuando nossa tradição histórico-normativa, o Estado de Direito, garantidor da ordem, usualmente prevalece sobre o Estado Democrático de Direito.

Por um lado, não raro, grevistas são vistos com desconfiança pela sociedade em geral, estimulada pela imprensa de massa que os descreve como baderneiros, causadores de prejuízos fatais às empresas. ${ }^{2}$ Por outro lado, pouco se trata do conflito trabalhista que motivou a greve, da situação do trabalhador, que opta pela greve, na grande maioria das vezes, como última alternativa, diante da situação degradante em que se encontra em termos salariais, morais e de saúde (Lima, 2014).

A restrição excessiva ao direito de greve e a negação dos conflitos coletivos geram diversas disfuncionalidades não somente no ambiente de trabalho, como também para a democracia. Kolben (2016) argui que o direito de greve possui uma função democrática essencial para o desenvolvimento. Para o autor, a promoção da democracia e da cidadania, tanto no local de trabalho, quanto na sociedade, possibilitam uma estrutura de desenvolvimento que privilegie as liberdades necessárias à plena concretização das capacidades dos indivíduos (Kolben, 2016).

Kolben argui que a inter-relação entre o direito do trabalho e a democracia é uma

1. Para uma análise do conceito de democracia no sistema constitucional brasileiro, ver Lima (2003).

2. Ver, por exemplo, a análise de Consenza (2004) sobre a imprensa e a greve dos petroleiros de 1995. 
questão originária da regulação do trabalho. Conforme o autor, «Workplace democracy and democratic values permeate the objectives and raison d'être of labour regulation and industrial relations» (Kolben, 2016: 72). A sua análise sugere que a regulação do trabalho pode construir instituições que levem ou funcionem como pontes para a democracia política («workplace bridge institutions», Kolben, 2016: 77).

Este artigo propõe que a liberdade sindical e o direito de greve podem constituir tais instituições, considerando-se que a democracia trabalhista se inter-relaciona com à democracia política (Dahl, 1985). Por um lado, a liberdade sindical, a negociação coletiva e a greve somente são plenamente assegurados em sistemas democráticos (Curtis, 2004). Essa estreita relação significa que a liberdade de associação vai além do local de trabalho, ou seja, promover os direitos de liberdade de associação é promover maior participação, debate e necessidade de diálogo não apenas no local de trabalho, mas também na tomada de decisões da política social (Gomes, 2009). Por outro, o exercício da liberdade sindical e das ações coletivas quando exercidas no local de trabalho molda a consciência individual dos trabalhadores e contribui para o maior envolvimento com o sistema político, reduzindo a alienação e possibilitando o exercício da cidadania (Kolben, 2016: 75).

A liberdade sindical e o direito de greve, portanto, podem ser compreendidos como liberdades essenciais à concretização da democracia, tanto no local de trabalho, quanto no sistema político. Ambos são meios e objetivos para o pleno desenvolvimento de um país, não somente no que tange ao aspecto econômico, mas também social.

\section{Liberdade sindical e direito de greve: Regulamentação aplicável ao contexto democrático brasileiro}

O direito de greve integra o princípio da liberdade sindical. A greve constitui uma das manifestações da liberdade coletiva dos trabalhadores representados pelo sindicato. Conforme destaca o Comitê de Liberdade Sindical referente à greve, embora o direito de greve não seja mencionado expressamente na Convenção 87 da OIT, o artigo $3^{\circ}$ dessa norma internacional dispõe que as organizações de trabalhadores têm o direito de formular seus programas de ação, sendo a greve uma atividade essencialmente importante para a organização dos trabalhadores. A Convenção 98 da OIT, por sua vez, coíbe práticas discriminatórias em razão da atividade sindical dos trabalhadores, protegendo a liberdade sindical nas relações intersubjetivas.

Apesar do posicionamento consolidado da doutrina e dos peritos da OIT de que o direito de greve é assegurado pela Convenção 87, a interpretação do Comitê de Liberdade Sindical vem sendo questionada pelo grupo de delegados dos empregadores na OIT desde 2012, defendendo uma visão extremamente individualista da liberda- 
de sindical e descontextualizada na negociação coletiva (Vogt, 2016) e da própria democracia. $^{3}$

Em âmbito nacional, a Constituição Federal de 1988 reconhece a liberdade sindical e o direito de greve como direitos fundamentais sociais. $\mathrm{O}$ artigo $8^{\circ}$ assegura ser livre a associação sindical, sendo vedado ao Poder Público interferir na criação e organização dos sindicatos. $\mathrm{O}$ artigo $9^{\circ}$ da Constituição assegura aos trabalhadores $\mathrm{o}$ direito de fazerem greve e a decisão acerca do momento de deflagração e dos interesses a serem por meio dela defendidos. A liberdade do exercício da greve e de decidir o quando e o porque são também assegurados, em conformidade com a Constituição, pelo artigo $1^{\circ}$ da lei $7.783 / 1989$ que regula o exercício do direito de greve.

Marques de Lima (2014: 60) destaca que o direito de greve pode ser classificado como direito fundamental de $2^{\text {a }}$ dimensão, posto que é um direito social «requer prestações do Estado, no fito de suprir carências da sociedade», ao mesmo tempo em

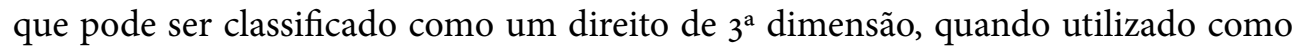
instrumento político para o exercício da participação democrática. Além disso, é garantia constitucional quando se destina a viabilizar e instrumentalizar outros direitos.

O direito de greve assume uma dimensão mais ampla, não se limitando simplesmente à defesa estrita dos interesses profissionais da classe trabalhadora. Lima (2014) entende que a liberdade sindical e o direito de greve são essenciais ao pleno exercício da democracia, sendo considerados não apenas como direitos fundamentais sociais a serem exercidos em face dos particulares, com também direitos de $3^{\text {a dimensão que }}$ podem ser utilizados em face do Estado. O Comitê de Liberdade Sindical admite o exercício da greve para a defesa de interesses de política econômica e social que afetem os trabalhadores (OIT, 2018), conforme dispõe o $\$ 758$ do seu Digesto:

758. Los intereses profesionales y económicos que los trabajadores defienden mediante el derecho de huelga abarcan no sólo la obtención de mejores condiciones de trabajo o las reivindicaciones colectivas de orden profesional, sino que engloban también la búsqueda de soluciones a las cuestiones de política económica y social y a los problemas que se plantean en la empresa y que interesan directamente a los trabajadores.

Essa compreensão do direito de greve está de acordo com a função democrática exercida pelo Direito Coletivo do Trabalho e prevista no artigo $1^{\circ}$, inciso IV da Constituição Federal de 1988, que descreve o trabalho como um valor social que fundamenta o Estado Democrático de Direito. Restringir a liberdade sindical e o direito de greve implica em violar esses valores.

3. Para uma análise do processo de negociação entre os grupos de delegados dos trabalhadores, empregadores e governos sobre a questão na OIT, ver Vogt, 2016. 
O valor social do trabalho contraria o argumento de que a dimensão econômica predomina no que concerne à elaboração de políticas sociais e regulações trabalhistas, perpassando assim a esfera política (Chiara e Macedo, 2019). A própria redemocratização do país é fruto de conflitos classistas originados a partir da resistência operária e de intensas reivindicações e greves, ${ }^{4}$ não existindo, na prática, luta econômica desvinculada da luta política e vice-versa.

A liberdade sindical e o direito de greve não são absolutos - assim como nenhum outro direito fundamental - ao conviverem em um sistema constitucional que reconhece outros direitos fundamentais amiúde conflitantes entre si. ${ }^{5}$ A Constituição Federal de 1988 limitou o exercício desses direitos. No caso da liberdade sindical, o artigo $8^{\circ}$, inciso II, da Constituição impõe a unicidade sindical, restringindo a liberdade sindical individual dos trabalhadores de criar sindicatos e violando o princípio da liberdade sindical assegurado na Convenção 87 da OIT. ${ }^{6}$ No caso do direito de greve, o Artigo $9^{\circ}$ da Constituição limita o exercício da greve nos casos de atividades essenciais (artigo $9^{\circ}, \$ 1^{\circ} \mathrm{da} C \mathrm{CF}$ ), remetendo à regulação infraconstitucional. A Lei 7.783/1989, denominada Lei de Greve, dispõe em seus artigos $9^{\circ}$, 10 e 11 que, durante a greve, o sindicato deverá entrar em acordo com o empregador ou entidade patronal de modo a disponibilizar equipes de funcionários destinadas a manter em funcionamento serviços ou atividades essenciais que, caso não atendidas, possam colocar em perigo iminente a segurança, a saúde ou a sobrevivência da população.

Além dos limites legais, Lima (2014: 66) observa que quando há colisão, no caso concreto, entre o direito de greve e outros direitos fundamentais individuais e coletivos, deve o intérprete, por meio de um juízo de ponderação, analisar a proporcionalidade da medida concreta de modo a preservar o «conteúdo essencial» ${ }^{7}$ dos direitos fundamentais envolvidos (Gomes, 2001). No caso do direito de greve, a permissão de paralisação coletiva do trabalho para a defesa dos interesses e direitos dos trabalhadores (Lima, 2014).

Não se deve confundir, no entanto, a necessária regulação do exercício do direito e ponderação realizada pelo aplicador em um caso concreto que envolva conflito de direitos fundamentais com uma racionalidade restritiva que, dentre outros aspectos, limite o direito de greve ao âmbito das relações entre empregado e empregador. A liberdade sindical e o direito de greve exercem uma função política em uma demo-

4. Sobre as greves no final dos anos 1970, ver Gomes e Prado, 2019.

5. Sobre o tema da restrição a direitos fundamentais, ver Novais, 2003.

6. Liberdade garantida na Convenção 87, Artigo $2^{\circ}$ : «Os trabalhadores e os empregadores, sem distinção de qualquer espécie, terão direito de constituir, sem autorização prévia, organizações de sua escolha...».

7. Como observa Alfonso (1981: 170), a garantia do conteúdo essencial de um direito fundamental «ofrece, como es claro, tanto un aspecto negativo de prohibición o limitación al legislador ordinario cuanto positivo de afirmación de una sustancia inmediatamente constitucional en dichos derechos». 
cracia. Essa dimensão, especificamente, no caso do direito de greve ainda constitui uma questão não resolvida. O próprio adjetivo «político» no caso da greve parece ter um sentido pejorativo, como explica Lourenço Filho (2014:157) ao analisar a greve dos petroleiros de 1995:

Para os que condenavam a paralisação, uma forma de fazê-lo era considerá-la política (como se fosse um vício que significasse por si); para os que defendiam a greve, tentava-se evitar a qualidade de política (da mesma forma: como se tratasse de um aspecto evidente). A despeito do texto constitucional de 1988 e das discussões que tiveram lugar na Assembleia Nacional Constituinte de 1987/1988, parecia permanecer a mentalidade de que a greve política não seria uma forma legítima de reivindicação. É válido contrastar essa mentalidade com a perspectiva de que o novo texto constitucional atribuiu aos trabalhadores a decisão sobre porque deflagrar uma greve, não limitando as possibilidades de motivação do movimento.

Como observa o autor, não obstante o texto constitucional, resta a discussão acerca da legitimidade da greve política que será analisada a seguir a partir de uma decisão do TST sobre o tema.

\section{A decisão proferida pelo TST e suas implicações para o exercício da democracia}

Em decisão proferida em 11/02/2019, a Seção Especializada em Dissídios Coletivos (SDC) do TST, ${ }^{8}$ por maioria, decidiu pela ilegalidade da greve deflagrada em junho de 2018 por trabalhadores do setor elétrico no intuito de impedir a privatização de empresas do sistema Eletrobrás (Centrais Elétricas Brasileiras). Nesse movimento paredista, a intenção dos obreiros era barrar a tramitação de projetos que tratavam da privatização da Eletrobrás, quais sejam: o Projeto de Lei 9.463/2018 a respeito da desestatização da Eletrobrás, o Decreto 9.188/2017 sobre desinvestimento das empresas de economia mista e o Projeto de Lei 1.917/2015 que abrange a portabilidade da conta de energia.

O relator, Ministro Maurício Godinho Delgado, votou pelo reconhecimento da legalidade da greve, sendo acompanhado pela Ministra Katia Magalhães Arruda. O Ministério Público do Trabalho opinou no mesmo sentido, por considerar a greve legal. No entanto, o voto divergente do Ministro Ives Gandra da Silva Martins Filho foi acompanhado pela maioria dos ministros, que julgaram por reconhecer a abusividade da greve.

Alegou o Ministro Ives Gandra da Silva Martins Filho, em seu voto, tratar-se «de

8. TST, Dissídio Coletivo de Greve (DCG), Ação declaratória de nulidade de greve. Autos do processo 1000418-66.2018.5.00.0000. Acórdão publicado em 14/02/2019. 
uma greve política, em que o objetivo é contestar a política de privatização do governo, especialmente no setor elétrico», portanto, continuou afirmando que «a paralização deixa de ser um direito laboral, para se transformar em modalidade de «lobby» ou grupo de pressão, como outro qualquer que vise obter ou impedir a normatização legal de determinada questão». Concluiu destacando que «a natureza não trabalhista de uma greve política fica clara na medida em que o polo passivo direto da greve, que são as empresas, não tem como negociar as reivindicações obreiras, pois dirigidas ao poder público»e «assim, verifica-se que o movimento paredista é nitidamente abusivo, pois desvirtua o direito de greve, para transformá-lo em instrumento de manifestação política, no qual saem prejudicadas as empresas e a população que utiliza os serviços paralisados».

A posição da maioria da SDC nesta decisão exclui do sentido do direito fundamental à greve a defesa de interesses não estritamente relacionados à relação de emprego. Isto é, a interpretação adotada restringe o sentido do texto do artigo $9^{\circ}$ da nossa Constituição Federal que dispõe o seguinte «É assegurado o direito de greve, competindo aos trabalhadores decidir sobre a oportunidade de exercê-lo e sobre os interesses que devam por meio dele defender». A questão que se coloca é se essa restrição ao sentido do texto que garante o direito de greve, limitando-o às relações estritas entre empregado e empregador, está de acordo com a Constituição; ou se, mais conforme à Constituição, é assegurar a abrangência do direito de greve de forma a admitir a liberdade dos trabalhadores acerca do melhor momento de deflagração do movimento e dos interesses serem defendidos. Este estudo propõe dois argumentos para o exame dessa questão: o primeiro argui que a SDC do TST adotou uma interpretação restritiva do direito de greve; o segundo argumento defende que a decisão ignorou a distinção entre interesses puramente políticos e interesses de política econômica e social que afetem os trabalhadores.

Um primeiro argumento a ser considerado, desenvolvido por Chiara e Macedo (2019), ao recordar ser o direito de greve um direito fundamental assegurado no Título II da Constituição, observa que a sua interpretação deve sempre buscar a maior efetividade, não cabendo interpretação restritiva nem inovação de seus termos para diminuir ou restringir seus efeitos. Na história constitucional brasileira, resta claro que a Constituição de 1988 visa garantir maior amplitude ao direito de greve no Brasil, conforme explica Delgado (2014: 204):

A Constituição brasileira de 1988, em contraponto a todas as constituições anteriores do país, conferiu, efetivamente, amplitude ao direito de greve. É que determinou competir aos trabalhadores a decisão sobre a oportunidade de exercer o direito, assim como decidir a respeito dos interesses que devam por meio dele defender ( $c a-$ put do art $9^{\circ}, \mathrm{CF} / 88$ ). Oportunidade de exercício da greve e interesses a serem nela defendidos, ambos sob decisão dos respectivos trabalhadores, diz o Texto Máximo da República. 
O cerne do voto divergente do Ministro Ives Gandra da Silva Martins Filho consiste em afirmar que se trata de uma greve de caráter político e que somente o polo passivo (empresa empregadora) poderia negociar as reivindicações obreiras, não podendo, portanto, o movimento paredista se insurgir contra uma ação praticada pelo Estado. Ou seja, a decisão majoritária da SDC adota uma interpretação restritiva do texto do artigo $9^{\circ}$. É uma interpretação restritiva, uma vez que há um sentido acerca do direito de greve englobando a defesa de interesses de política econômica e social no âmbito da OIT, conforme o Digesto do Comitê de Liberdade Sindical já citado. $\mathrm{Na}$ doutrina, também se encontra a discussão acerca do direito de greve política. Por exemplo, a análise de Litor (2019) exatamente acerca de greves antiprivatizações, examinando os casos de Israel e do Reino Unido. Outrossim, a greve política também tem sua legitimidade aceita por cortes em outros países. Nascimento (2000: 373), citando decisão proferida em 1974 pela Corte Constitucional italiana, explica que a Corte «declarou inaplicáveis dispositivos da legislação penal que incriminavam greves não contratuais, portanto, aquelas que, como a greve política, não visavam fins econômico-trabalhistas». Aquela Corte Constitucional teria, ainda, afirmado que «a greve constituía, sempre, uma manifestação de liberdade constitucionalmente reconhecida e, como tal, não suscetível de constrangimentos jurídicos, salvo em se tratando de casos de subversão do ordenamento constitucional». Na Espanha, para a Corte Constitucional «only political strikes totally unrelated to workers' rights and interests, and sympathy strikes with no connection at all among the strikers, are deemed to be illegal. In practice, such cases are rare» (Laulom e Lo Faro, 2014: 281).

O segundo argumento a ser feito reconhece que para que a greve política seja legítima, ou seja, para que esteja dentro da abrangência do direito de greve, é essencial que os interesses de política social ou econômica se relacionem diretamente com os trabalhadores grevistas. É o que esclarece o $\$ 766$ do Digesto (OIT, 2018) do Comitê de Liberdade Sindical:

766. El derecho de huelga no debería limitarse a los conflictos de trabajo susceptibles de finalizar en un convenio colectivo determinado: los trabajadores y sus organizaciones deben poder manifestar, en caso necesario en un ámbito más amplio, su posible descontento sobre cuestiones económicas y sociales que guarden relación con los intereses de sus miembros.

A greve puramente política está fora da abrangência do direito de greve; não é greve. Nesse sentido, os $\$ \$ 760$ e 761 do Comitê de Liberdade Sindical (OIT, 2018):

760. Las huelgas de carácter puramente político y las huelgas decididas sistemáticamente mucho tiempo antes de que las negociaciones se lleven a cabo no caen dentro del ámbito de los principios de libertad sindical. 
761. Las huelgas de carácter puramente político no entran en el ámbito de la protección deparada por los Convenios núms. 87 y 98.

$\mathrm{Na}$ decisão examinada, o relator do processo, o Ministro Mauricio Godinho Delgado, em seu voto vencido, sustenta que «se a greve, ainda que detenha um viés político ou de solidariedade, mostra real conexão com temas de importante interesse profissional dos grevistas, naturalmente que ela deve ser tida como harmônica ao disposto no art. $9^{\circ}$ da Constituição de 1988». E prossegue com seu voto:

Sob o ponto de vista constitucional, as greves não necessitam se circunscrever a interesses estritamente contratuais trabalhistas (embora tal restrição seja recomendável, do ponto de vista político-prático, em vista do risco da banalização do instituto-aspecto a ser avaliado pelos trabalhadores). No caso concreto, transparece a presença de relevantes interesses profissionais no contexto da greve, porque, obviamente, interessa ao trabalhador, particularmente ao empregado, preservar a empresa. E a defesa da empresa, por parte do trabalhador, é uma conduta e um pleito que ostentam nítido sentido econômico-profissional.

Neste mesmo sentido, no âmbito do Supremo Tribunal Federal, o Ministro Eros Grau ao analisar o Mandado de Injunção 712 sustentou em seu voto que mesmo a greve por motivos políticos é válida, estando albergada na nossa Constituição Federal de 1988:

A Constituição, tratando dos trabalhadores em geral, não prevê regulamentação do direito de greve: a eles compete decidir sobre a oportunidade de exercê-lo e sobre os interesses que devam por meio dela defender. Por isso a lei não pode restringi-lo, senão protegê-lo, sendo constitucionalmente admissíveis todos os tipos de greve: greves reivindicatórias, greves de solidariedade, greves políticas, greves de protesto.

O Comitê de Liberdade Sindical utiliza a mesma racionalidade, qual seja, o direito de greve engloba a greve política que defende interesses dos grevistas relacionados a políticas econômicas e sociais, na análise de greves gerais. Nesse sentido, os $\$ \$ 779$ a 782 do Comitê de Liberdade Sindical (OIT, 2018):

779. El Comité ha mantenido en reiteradas ocasiones la legitimidad de las huelgas de ámbito nacional, en la medida que tengan objetivos económicos y sociales y no puramente políticos; la prohibición de la huelga sólo podría ser aceptable con respecto a los funcionarios públicos, , que actúan como órganos del poder público, o con respecto a los trabajadores de los servicios esenciales en el sentido estricto del término (es decir, aquellos servicios cuya interrupción podría poner en peligro la vida, la seguridad o la salud de la persona en toda o parte de la población).

780. La declaración de ilegalidad de una huelga nacional en protesta por las consecuencias sociales y laborales de la política económica del gobierno y su prohibición constituyen una grave violación de la libertad sindical. 
781. En lo que respecta a la huelga general, el Comité ha considerado que la huelga es uno de los medios de acción del que deben poder disponer las organizaciones de trabajadores. Es legítima y corresponde a la esfera de actividad normal de las organizaciones sindicales una huelga general de 24 horas reivindicando el aumento de los salarios mínimos, el respeto de los convenios colectivos en vigor y el cambio de política económica (disminución de precios y del desempleo).

782. La convocatoria de una huelga general de protesta para que se ponga fin a los centenares de asesinatos de dirigentes sindicales y sindicalistas que se han producido en los últimos años constituye una acción sindical legítima por lo que su prohibición constituye una violación grave de la libertad sindical.

O caso concreto, em análise, não pode ser classificado como movimento paredista estritamente de caráter político, uma vez que a privatização tem o potencial de ameaçar a existência das empresas e dos postos de trabalho dos grevistas. Ao analisar caso semelhante, o TST, nos autos do processo TST-RODC 781712, publicado no Diário da Justiça de 23/04/2004 em que foi relator o ministro José Luciano de Castilho Pereira, já decidiu no sentido de afastar o entendimento segundo o qual a greve em face da privatização de um banco estatal seria uma greve política, classificando-a como greve de caráter trabalhista.

Em tal contexto, é óbvio que a mudança na estrutura do Banco interessa e muito aos empregados, pois não se cuidará de uma mera troca de empregadores, mas de alteração da própria natureza jurídica do Banco, tendo em vista que o empregado deixará de fazer parte da administração pública indireta para se vincular a um empregador privado, cuja política de pessoal costuma ser menos favorável ao trabalhador. Tais fatos demonstram o legítimo interesse dos empregados em discutir esse processo e procurar formular reivindicações para protegê-los. Nesse contexto, a greve deflagrada não tem nenhum caráter político, e sim trabalhista, estando autorizada, em consequência, pelo art. 14, parágrafo único, II, da Lei de Greve.

Argumentar que a greve contra a privatização da Eletrobrás não expressa um conflito trabalhista, mas possui conotação política com intuito de fazer «lobby» ou "grupo de pressão», ignora a diferenciação entre interesses puramente políticos e interesses de política econômica e social que impactam na vida dos trabalhadores, como é o caso das privatizações.

A privatização de uma empresa estatal afeta diretamente as relações de trabalho, sendo legítima a resistência dos trabalhadores contra sua adoção e efeitos. O direito de greve, como instrumento máximo de pressão, é praticamente o único meio eficiente de que dispõem os trabalhadores nos casos de arbítrio do poder econômico vinculado ao poder político do Estado.

Conforme dossiê elaborado pela Central Única dos Trabalhadores (CUT, 2014) sobre a terceirização no Brasil, a privatização traz consequências graves no que se 
refere à precarização das condições de trabalho, uma vez que os trabalhadores terceirizados comprovadamente ganham menores salários, possuem menores garantias, com maior rotatividade nos postos de trabalho e estão mais expostos a sofrer acidentes de trabalho, especialmente em setores de risco, como o setor elétrico. Conforme consta na introdução do referido dossiê (CUT, 2014: 09):

[...] Do ponto de vista econômico, as empresas procuram otimizar seus lucros pelo crescimento da produtividade, pelo desenvolvimento de produtos com maior valor agregado - com maior tecnologia - ou ainda devido à especialização dos serviços ou produção. Buscam, como estratégia central, otimizar seus lucros e reduzir preços, em especial, por meio de baixíssimos salários, altas jornadas e pouco ou nenhum investimento em melhoria das condições de trabalho, que passam a ser de responsabilidade da subcontratada. Do ponto de vista social, podemos afirmar que a grande maioria dos direitos dos terceirizados é desrespeitada, criando a figura de um «trabalhador de segunda classe» com destaque para as questões relacionadas à vida dos trabalhadores (as), aos golpes das empresas - que fecham do dia para a noite e não pagam as verbas rescisórias aos seus trabalhadores empregados - e às altas e extenuantes jornadas de trabalho.

Com a promulgação da Lei 13. 429/2017, a terceirização dos contratos de trabalho passou a abranger, inclusive, as atividades-fim das empresas, ou seja, as atividades essenciais ao seu funcionamento. Por essa razão, a preocupação com relação à precarização das condições de trabalho, advindas da possível privatização e terceirização dos postos de trabalho, aumenta ainda mais, visto que abrangerá um número ainda maior de trabalhadores.

É lícito considerar que o exercício da greve política pode gerar custos aos empregadores em razão de uma situação sobre a qual os mesmos não têm controle. A solução para esse problema, todavia, não parece ser a mera proibição da greve política, ignorando-se o sentido do texto do caput do Artigo $9^{\circ}$ da Constituição Federal. Pode-se adotar medidas que buscam uma proporcionalidade entre o direito fundamental de greve e o direito de propriedade do empregador, em tais situações, por exemplo, limitando as horas da paralisação.

Considerando os dois argumentos acima, a decisão do TST, ao restringir o sentido da greve a questões laborais entre empregados e empregado, não está conforme o art. $9^{\circ}$ da Constituição Federal e com a legislação internacional do trabalho, em especial com a interpretação do Comitê de Liberdade Sindical da OIT. Ademais, a decisão ignora que o direito do trabalho deve proteger a participação democrática dos trabalhadores tanto no contexto político, quanto social, limitando o exercício do direito democrático de participar ativamente das decisões políticas do país e de exercer plenamente a cidadania, na medida em que limita a manifestação do direito de greve às relações de trabalho entre empregados e empregadores (Kupferberg, 1985). O 
reconhecimento da função democrática exercida pelo direito do trabalho, ao garantir o exercício de direitos e liberdades fundamentais pelos trabalhadores, amplia o campo de exercício da cidadania, fortalece a democracia e promove o desenvolvimento (Kolben, 2016).

\section{Considerações finais}

A pesquisa dividiu-se em três capítulos. O primeiro capítulo examinou as possibilidades e os limites do direito de greve e da liberdade sindical como manifestações do exercício da democracia. O segundo capítulo analisou a regulamentação do direito de greve e da liberdade sindical, considerando a legislação pátria e as normas internacionais, em especial a Convenção da OIT 98 da OIT, ratificada, e a Convenção 87 da OIT não ratificada pelo Brasil.

A liberdade sindical e o direito de greve constituem instituições que possibilitam o exercício da democracia, não limitando seus efeitos à solução de conflitos entre empregado e empregador, mas promovendo também a participação dos cidadãos nas discussões e delineamento de políticas econômicas e sociais que afetem os trabalhadores. O direito de greve, em especial, possui diferentes dimensões, ao se caracterizar como um direito fundamental de $2^{\text {a }}$ dimensão - um direito social -, mas também como um direito de $3^{\text {a }}$ dimensão democracia, quando utilizado como instrumento político para o exercício da participação democrática, e, ainda, como uma garantia constitucional, quando visa instrumentalizar o exercício de outros direitos.

Restringir o exercício do direito de greve aos conflitos que envolvam exclusivamente o empregado e o empregador, impossibilitando sua utilização como forma de pressionar o Estado a atuar positivamente, no sentido de garantir os direitos fundamentais sociais dos trabalhadores, implica em restringir o exercício do direito democrático de participar ativamente das decisões políticas do país e de exercer plenamente a cidadania.

Essa função democrática que potencialmente pode ser exercida pela regulação do trabalho é essencial para a promoção da democracia e da cidadania, tanto no local de trabalho, quanto na sociedade. O desenvolvimento não é alcançado por meio da aplicação de uma visão meramente economicista segundo a qual a regulação do trabalho, tanto a individual, quanto a coletiva, somente significam custos. Mais do que isso, é necessário ampliar o espectro de liberdades a serem alcançadas pelos trabalhadores, entre elas as liberdades políticas, para que, dessa forma, tenham condições de construir capacidades individuais e coletivas essenciais ao exercício da cidadania, o que resulta em um Estado Democrático fortalecido.

A decisão proferida pelo TST nos autos do processo 1000418-66.2018.5.00.000o vai na contramão desses preceitos quando restringe a manifestação do direito de greve às relações de trabalho entre empregado e empregador, em entendimento oposto 
ao consolidado pelo Comitê de Liberdade Sindical, ignorando a possibilidade do Estado de figurar em um dos polos dessa relação. Trata-se de entendimento que nega uma das mais importantes funções do direito de greve, qual seja, possibilitar aos trabalhadores o pleno exercício da cidadania, através da participação política. No caso em análise, os trabalhadores defendiam seu direito fundamental ao trabalho, uma vez que a privatização da empresa resultaria na extinção da própria empregadora, com o fim dos postos de trabalho, não sendo razoável que esses trabalhadores não tenham em face de quem reclamar.

Assumir essa perspectiva mais ampla da liberdade sindical e do direito de greve não implica em reconhecer esses direitos como absolutos, uma vez que a própria Constituição Federal de 1988, a legislação infraconstitucional e as normas internacionais que tratam do assunto estabelecem limites claros ao exercício desses direitos.

\section{Referências}

Alfonso, L. Parejo (1981). «El contenido esencial de los derechos fundamentales en la jurisprudencia constitucional: a propósito de la sentencia del Tribunal Constitucional de 8 de abril de 1981». Revista Española de Derecho Constitucional, 1 (3): 169-190.

Baboin, José Carlos de Carvalho (2013). O tratamento jurisprudencial da greve política no Brasil. São Paulo: USP/Dissertação (Mestrado em Direito). Programa de Pós-Graduação em Direito. Faculdade de Direito.

CUT, Central Única dos Trabalhadores (2014). Dossiê acerca do impacto da terceirização sobre os trabalhadores e propostas para garantir a igualdade de direitos. Terceirização e desenvolvimento: uma conta que não fecha. São Paulo: Central Única dos Trabalhadores. Disponível em https://bit.ly/2WzjKiO.

Chiara, Alexandre Henrique Podadera de e Regiane de Moura Macedo (2019). O Tribunal Superior do Trabalho e a insustentável doutrina da "greve política». Disponível em https://bit.ly/35YxCWL.

Cosenza, Ana (2004). «Representações da greve dos petroleiros de 1995 na imprensa: as referências ao período militar e à democracia no discurso jornalístico». Proj. História, 29 (1): 303-312.

CURTIS, Karen (2004). «Democracy, freedom of association and the ILO». Em: Javillier, Jean-Claude e Gernigon Bernard (coordenadores), Les normes internationales du travail: un patrimoine pour l'avenir. Mélanges en l'honneur de Nicolas Valticos. Genève: Bureau international du Travail.

DaHL, Robert (1985). A Preface to Economic Democracy. Berkeley, Ca: University of California Press.

Delgado, Mauricio Godinho (2001). «Direito Coletivo do Trabalho e seus princípios informadores». Revista TST, Brasília, 67 (2): 79-98. 
-. (2014). Direito coletivo do trabalho. São Paulo: LTR.

Gomes, Ana Virginia Moreira (2001). A Aplicação do Princípio Protetor no Direito do Trabalho. São Paulo: LTR.

-. (2009). The effect of ILO's Declaration on Fundamental Principles and Rights at Work on the evolution of legal policy in Brazil: An analysis offreedom of association. Toronto: University of Toronto, Faculty of Law, LL.M. Thesis.

Gomes, Ana Virginia Moreira e Mariana Mota Prado (2019). «Institutional bypasses in Brazil's New Unionism movement: Central unions and workers' committees». University of Toronto Law Journal, 69 (3): 337-370.

KolbeN, Kevin (2016). «Labour regulation, capacibilities, and democracy». Em Marshall Shelley e Colin Fenwick. Labour Regulation and Development, Socio-legal Perspectives. Northampton Massachusetts: Edward Elgar Publishing/International Labour Office, 2016. Disponível em https://bit.ly/2Z6Wmuf.

KupferberG, Seth (1985). «Political strikes, labor law, and democratic rights». Virginia Law Review, 71 (5): 685-752.

Laulom, Sylvaine e Antonio Lo Faro (2014). «Remedies for Unlawful Collective Action in France, Belgium, Italy, and Spain». The International Journal of Comparative Labour Law and Industrial Relations, 30 (3): 273-292.

Lima, Francisco Gerson Marques de (2014). Greve: um direito antipático. Fortaleza: Premius.

Lima, Martonio Mont'Alverne Barreto (2003). «Jurisdição Constitucional: Um Problema da Teoria da Democratica Política». Em Souza Neto, Cláudio Pereira de; Bercovici, Gilberto; Moraes Filho, José Filomeno de e Lima, Martonio Mont'Alverne Barreto (coordenadores). Teoria da Constituição: Estudos Sobre o Lugar da Política no Direito Constitucional (pp. 199-261). Rio de Janeiro: Lumen Juris.

Lourenço Filho, Ricardo Machado (2014). Entre continuidade e ruptura: uma narrativa sobre as disputas de sentido da Constituição de 1988 a partir do direito de greve. Brasília: Tese de Doutorado apresentada ao Programa de Pós-Graduação em Direito da Faculdade de Direito da Universidade de Brasília.

LiTOR, Lilach (2019). «Constitutionalism and Anti-Privatisation Strikes: Introducing an Eclectic Model». Israel Law Review, 52 (3):327-366.

Nascimento, Amauri Mascaro (200o). Compêndio de Direito Sindical. São Paulo: LTR.

NovaIs, Jorge Reis (2003). As restrições aos direitos fundamentais não expressamente autorizadas pela constituição. Coimbra: Coimbra, 2003.

OIT, Organización Internacional del Trabajo (2018). La libertad sindical. Recopilación de decisiones del Comité de Libertad Sindical. Ginebra: OIT.

Vogt, Jeffrey S. (2016). «The Right to Strike and the International Labour Organisation (ILO)». King's Law Journal, 27(1): 110-131. 


\section{Sobre os autores}

Ana Virgínia Moreira Gomes: Professora da Universidade de Fortaleza, Brasil; LL.M. pela Faculty of Law da University of Toronto, Canadá; Doutora em Direito pela Faculdade de Direito da Universidade de São Paulo, Brasil. Coordenadora do Núcleo de Estudos em Direito do Trabalho e Seguridade Social na Universidade de Fortaleza, Brasil. O seu endereço de correio electrónico é avmgomes@gmail.com.

Flavia Aguiar Cabral Furtado Pinto: Doutoranda em Educação pela Universidade Estadual do Ceará(UECE). Mestre em Direito Constitucional pela Universidade de Fortaleza (UNIFOR). Graduada em Direito (UNIFOR). Oficiala de Justiça Avaliadora Federal do Tribunal Regional do Trabalho da $7^{\text {a }}$ Região (CE). Professora universitária. O seu endereço de correio electrónico é flavia.aguiar.cabral@gmail.com.

Carlos Eduardo Furtado Pinto: Mestrando em Direito Constitucional (UNIFOR). Graduado em Direito pela Universidade de Fortaleza (2006). Oficial de Justiça Avaliador Federal do Tribunal Regional do Trabalho da $7^{a}$ Região (CE). O seu endereço de correio electrónico é carloseduardofurtadopinto@yahoo.com.br. 